\title{
Enhanced Photocatalytic Activity for Degradation of Methyl Orange over Silica-Titania
}

\author{
Yaping Guo, ${ }^{1}$ Shaogui Yang, ${ }^{2}$ Xuefei Zhou, ${ }^{3}$ Chunmian Lin, ${ }^{1}$ Yajun Wang, ${ }^{1}$ \\ and Weifeng Zhang ${ }^{1}$ \\ ${ }^{1}$ College of Biological and Environmental Engineering, Zhejiang University of Technology, Hangzhou 310014, China \\ ${ }^{2}$ State Key Laboratory of Pollution Control and Resources Reuse, Nanjing University, Nanjing 210093, China \\ ${ }^{3}$ State Key Laboratory of Pollution Control and Resources Reuse, Tongii University, Shanghai 200092, China
}

Correspondence should be addressed to Shaogui Yang, yangdlut@126.com

Received 1 November 2010; Accepted 2 March 2011

Academic Editor: Junping Wang

Copyright (C) 2011 Yaping Guo et al. This is an open access article distributed under the Creative Commons Attribution License, which permits unrestricted use, distribution, and reproduction in any medium, provided the original work is properly cited.

\begin{abstract}
Silica-modified titania (SMT) powders with different atomic ratios of silica to titanium (Rx) were successfully synthesized by a simple ultrasonic irradiation technique. The prepared samples were characterized by X-ray diffraction (XRD), FT-IR spectroscopy, transmission electron microscopy (TEM), X-ray photoelectron spectroscopy (XPS), and ultraviolet visible spectroscopy. The specific surface area was measured according to BET theory. Results indicate that the addition of silica to titania can suppress the crystalline size growth and the transformation of anatase phase to rutile phase of titania, enlarge specific surface area of the titania particles, and result in a blue shift of absorption edge compared to pure titania. The photocatalytic activity of the SMT samples was evaluated by decolorizing methyl orange aqueous solutions under UV-visible light irradiation. It was found in our study that this activity was affected by silica content, calcination temperature, $\mathrm{H}_{2} \mathrm{SO}_{4}$, and oxidants such as $\mathrm{KIO}_{4},\left(\mathrm{NH}_{4}\right)_{2} \mathrm{~S}_{2} \mathrm{O}_{8}$ and $\mathrm{H}_{2} \mathrm{O}_{2}$. The results reveal that the photocatalytic activity of $0.1-\mathrm{SMT}$ catalyst is the best among all samples calcined at $550^{\circ} \mathrm{C}$ for $1 \mathrm{~h}$ and it is 1.56 times higher than that of Degussa P-25 titania, which is a widely used commercial $\mathrm{TiO}_{2}$ made by Germany Degussa company and has been most widely used in industry as photocatalyst, antiultraviolet product, and thermal stabilizer. The optimal calcination temperature for preparation was $550^{\circ} \mathrm{C}$. The photocatalytic activity of SMT samples is significantly enhanced by $\mathrm{H}_{2} \mathrm{SO}_{4}$ solution treatment and oxidants.
\end{abstract}

\section{Introduction}

As a cost-effective, nontoxic, effective photocatalyst, nanosize $\mathrm{TiO}_{2}$ has received much attention during the past three decades. In its practical application, it is very important to improve the efficiency of titania-based photocatalysts because titania usually has a small surface area and pore volume, which leads to its low adsorption of organic pollutants. Therefore, the enlargement of specific surface area and adsorption capability is desirable for titania photocatalyst.

Generally speaking, two strategies have been developed to solve the problem. One is the synthesis of malodorous titania with high specific surface area resulting in high adsorbability and photocatalytic activity [1], the other is the combination of titania materials with adsorbent [2]. For the former strategy, titania mostly exists in an amorphous or semicrystalline phase so it has low photocatalytic activity. It has been proven that the later method is relatively easy to prepare. As an adsorbent and stabilizer, silica is the best candidate as it not only possesses a large specific surface area, but also has no absorption in UV region. Titania-silica mixed oxide has attracted considerable attention as attractive materials for photocatalytic applications because of the synergetic function of the photocatalytic activity, adsorbability, and stability. This may be partially the intimate interaction of titanium dioxide and silica, the new different structural characteristics and physicochemical/reactivity properties of titania-silica complex, such as quantum-sized crystalline, large surface area, high thermal stability, high adsorbability of reactant, or high acidity $[3,4]$. Most of studies for titania-silica were concentrated on the structure type of titania supported on silica or titanium 
silicate series [5-8], the application of waste air purification [9] and wastewater treatment [10]. However, few studies on wastewater treatment with titania-silica have been reported.

The purpose of the paper is to explore SMT with high photoactivity for purifying the water. Methyl orange was chosen as a probe for its relatively high reactivity and high stability. We also found that the photocatalytic activity of the prepared SMT could be greatly improved by $\mathrm{H}_{2} \mathrm{SO}_{4}$ solution treatment. Explanations are provided based on the influence of sulfuric acid treatment on photocatalytic activity.

\section{Materials and Methods}

2.1. Materials. Tetraethylorthosilicate (TEOS), tetrabutylorthotitanate (TBOT), methyl orange, sulfuric acid, $\mathrm{KIO}_{4}$, $\left(\mathrm{NH}_{4}\right)_{2} \mathrm{~S}_{2} \mathrm{O}_{8}$, and $\mathrm{H}_{2} \mathrm{O}_{2}$ were from Shanghai Chemical Company at analytic purity.

\subsection{Methods}

2.2.1. Preparation of Silica-Modified Titania (SMT) and Surface Acid Treatment. Nanocrystalline Titania powders were prepared by hydrolysis under ultrasonic irradiation $[11,12]$. Tetrabutylorthotitanate (TBOT) was used as a titanium source. Tetraethylorthosilicate (TEOS) was used as a precursor of the dopant. The mixture of TBOT $(0.1125 \mathrm{~mol})$ and TEOS was directly added dropwise to distilled water $(900 \mathrm{~mL})$ under vigorous stirring at room temperature. The atomic ratios of silica to titanium, which hereafter was designated as $\mathrm{Rx}$, were $0,0.05,0.1$, and 0.2 , respectively. The samples were then irradiated with an ultrasonic cleaning bath (KQ3200E, $40 \mathrm{kHz}, 150 \mathrm{~W}$ ) for $1 \mathrm{~h}$, followed by aging in a closed beaker at room temperature for $24 \mathrm{~h}$. After aging, these samples were dried at $100^{\circ} \mathrm{C}$ for about $8 \mathrm{~h}$ in air in order to vaporize water in the gels and then ground to fine powders to obtain dry gel samples. The dried gel samples were calcined at different temperature in air for $1 \mathrm{~h}$.

To enhance the photocatalytic activity of the powders, we dipped the SMT in $1 \mathrm{~mol} \cdot \mathrm{L}^{-1} \mathrm{H}_{2} \mathrm{SO}_{4}$ aqueous solutions at room temperature. After $20 \mathrm{mins}$, the samples were withdrawn from the $\mathrm{H}_{2} \mathrm{SO}_{4}$ solutions. They were carefully rinsed with deionized water and dried at $100^{\circ} \mathrm{C}$ for $2 \mathrm{~h}$ in an oven in air.

2.2.2. Characterization. XRD patterns were made using a $\mathrm{X}^{\prime} \mathrm{TRA}$ diffractometer (made in ARL Company in Swiss) with $\mathrm{Cu} \mathrm{K} \alpha$ radiation over the scan range $20-60^{\circ} \mathrm{C}$ for wide angle XRD. The average crystalline size of powders was estimated by the Scherrer formula [13]: $D=0.89 \lambda / \beta \cos c$ (where $D$ is the crystallite size, $\lambda$ is the wavelength of the $\mathrm{X}$-ray radiation $(\mathrm{CuK} \alpha=0.15418 \mathrm{~nm}), K$ is usually taken as 0.89 , and $\beta$ is the line width at half-maximum height, after subtraction of equipment broadening). The FTIR spectra were recorded by a NEXUS 870 FT-IR, made in U.S. NICOLET Company in a wavenumber range of $4000-400 \mathrm{~cm}^{-1}$. UV-V is spectroscopic analysis that was

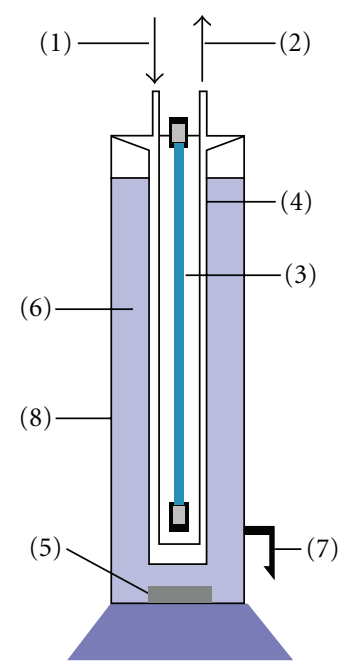

Figure 1: Photoreactor system for methyl orange degradation. (1) Cooling water input, (2) water outflow, (3) UV lamp, (4) Quartz sleeve, (5) Stirrer bar, (6) reactant solution, (7) exhaust, and (8) glass reactor.

performed by using a spectrophotometer (SHIMADZU UV2401). X-ray photoelectron spectroscopy (XPS) measurements were done with an ESC ALB MK-II XPS System with a monochromatic $\mathrm{Al} \mathrm{KR}$ source and a charge neutralizer. Measurement of BET (BET aims to explain the physical adsorption of gas molecules on a solid surface and serves as the basis for an important analysis technique for the measurement of the specific surface area of a material. In 1938, Stephen Brunauer, Paul Hugh Emmett, and Edward Teller published an article about the BET theory in a journal for the first time; "BET" consists of the first initials of their family names [12], surface area was performed using $\mathrm{N}_{2}$ adsorption/desorption isotherms on a Micromeritics ASAP 2020.

2.2.3. Photocatalytic Activity of Silica-Modified Titania (SMT). The photocatalytic activity of prepared SMT powders for decomposition of methyl orange was investigated as shown in Figure 1. The photocatalytic reactor has an effective volume of $150 \mathrm{ml}$. The experiment was performed in the following condition: UV irradiation (a $400 \mathrm{~W}$ high-pressure mercury lamp from factory of Beijing light with a maximum wavelength of $365 \mathrm{~nm}$, Io $=1.50 \mathrm{~mW} / \mathrm{cm}^{2}$ ), vigorous stirring, no airflow. The initial concentration of methyl orange was $20 \mathrm{mg} \cdot \mathrm{L}^{-1}$ and $\mathrm{Rx}$-SMT powders were kept $1.0 \mathrm{~g} / \mathrm{L}$ in all cases.

Degussa P25 titania particles $\left(50 \mathrm{~m}^{2} / \mathrm{g}\right)$ with crystalline structure of ca. $20 \%$ rutile and $80 \%$ anatase and primary particle size of ca. $21 \mathrm{~nm}$ was taken as a reference to test the photoactivity of the Rx-SMT powders towards the degradation of methyl orange.

The concentration of methyl orange was determined using UV-1600 spectroscopy at wavelength $\ddot{e}=440 \mathrm{~nm}$ quantitatively. Total organic carbon (TOC) was determined with Shimadzu TOC-5000 analyzer. 


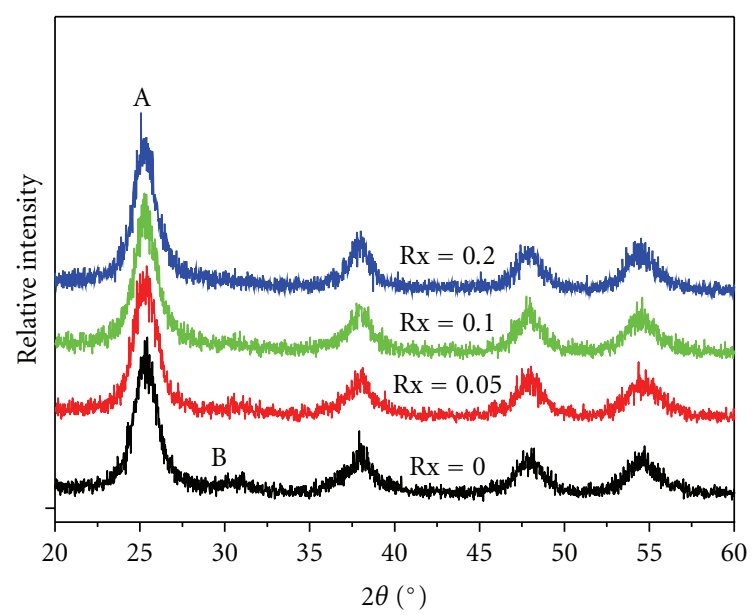

A: anatase

B: brookite

FIGURE 2: XRD patterns of the Rx-SMT xerogel powders $(\mathrm{Rx}=0$, $0.05,0.1$, and 0.2 ) and dried at $100^{\circ} \mathrm{C}$ for $8 \mathrm{~h}$.

\section{Results and Discussion}

3.1. Crystal Structure and TEM Photomicrography. XRD was used to investigate the changes of crystalline phase of the SMT gel powders before and after heat treatment. Figure 2 shows the effects of silica on phase structures of the $\mathrm{TiO}_{2}$ powders dried at $100^{\circ} \mathrm{C}$ for $8 \mathrm{~h}$. The anatase phase is dominant in the as-prepared $\mathrm{TiO}_{2}$ sample, but there is a small amount of brookite in it. The weak peak at $2 \mathrm{c}=30.7^{\circ}$ corresponds to the brookite phase of titania. When $\mathrm{Rx}>$ 0.1 , the intensities of brookite peaks steadily become weaker and finally disappear. This is probably due to the fact that silica suppresses the crystallization of brookite by adsorbing onto the surfaces of $\mathrm{TiO}_{2}$ particles. Similar result has been observed with F ion doping [14].

Figure 3 shows the effects of silica content on the phase structures of Rx-SMT powders calcined at $550^{\circ} \mathrm{C}$. For pure titania $(\mathrm{Rx}=0)$, significant peaks of rutile phase are observed obviously. The dominant phase of titania $(\mathrm{Rx}>0)$ is anatase when some portion of silica is embedded into titania particles. Apart from the diffraction peaks corresponding to anatase, there are no other diffraction peaks from $2 \check{c}=20-60$ degree for all SMT samples (except for pure titania) as shown in Figure 3, indicating that silica exists in an amorphous phase. The average size of anatase titania from Scherrer formula was presented in Table 1 . The result shows that the crystallite size decreased sharply with increasing the doping silica content up to 0.05 . When the silica content was over 0.05 , there was no significant change in the crystallite size of SMT particles. This result confirms that the embedding of some portion of silica into titania particle inhibits the growth of anatase crystal of titania particles [15].

Figure 4 shows the effects of calcination temperature on phase structures of 0.1-SMT powders. It can be seen that the peak intensities of anatase increase and the width of the (101) plane diffraction peak of anatase $\left(2 \theta=25.4^{\circ}\right)$ becomes

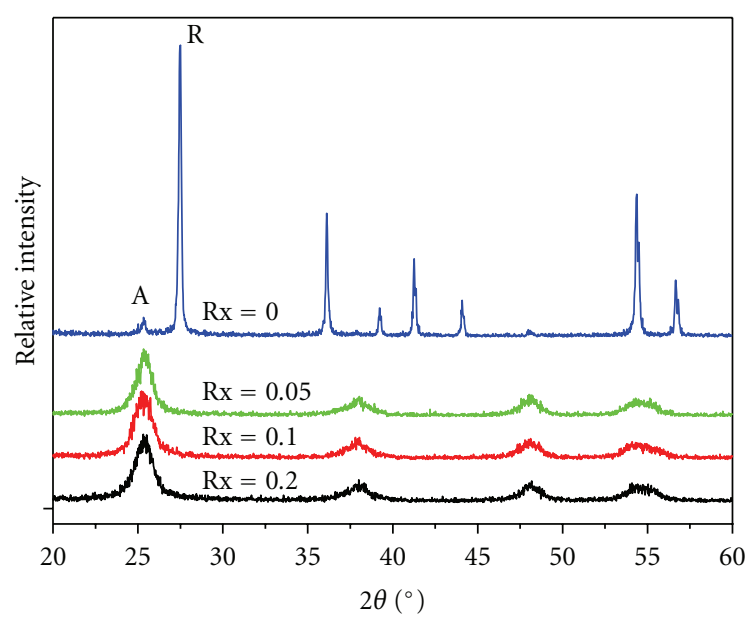

A: anatase

R: rutile

FIGURE 3: XRD patterns of Rx-SMT powders $(\mathrm{Rx}=0,0.05,0.1$, and 0.2 ) calcined at $550^{\circ} \mathrm{C}$ for $1 \mathrm{~h}$.

TABLe 1: Textural properties of the Rx-SMT powders prepared at $550^{\circ} \mathrm{C}$ for $1 \mathrm{~h}$.

\begin{tabular}{lccc}
\hline Samples & $\begin{array}{c}\text { Si/Ti } \\
\text { molecular } \\
\text { ratio by XPS }\end{array}$ & $\begin{array}{c}\text { Surface area } \\
\left(\mathrm{m}^{2} \cdot \mathrm{g}^{-1}\right)\end{array}$ & $\begin{array}{c}\text { Average size } \\
(\mathrm{nm})\end{array}$ \\
\hline 0-SMT & 0 & 20 & 50.5 \\
$0.05-\mathrm{SMT}$ & 0.053 & 160 & 8.9 \\
0.1-SMT & 0.094 & 196 & 7.2 \\
$0.1-\mathrm{SMT}_{\text {treated by }}$ & 0.093 & 195 & 7.2 \\
$\mathrm{H}_{2} \mathrm{SO}_{4}$ solution & 0.206 & 208 & 6.9 \\
$0.2-$ Silica titania & & &
\end{tabular}

narrower with increasing calcination temperature (from 100 to $750^{\circ} \mathrm{C}$ ). It has been reported that anatase-type $\mathrm{TiO}_{2}$ changes to rutile-type structure by heat treatment above $635^{\circ} \mathrm{C}$ from the results of a kinetic study on the anataseto-rutile phase transformation [13]. At $750^{\circ} \mathrm{C}$, anatase is a main phase and a small amount of rutile phase is detected, while the phase of pure titania calcained at $550^{\circ} \mathrm{C}$ was dominant rutile phase. The resulting SMT powders contain only anatase phase in the calcination temperature range of 100-650 ${ }^{\circ}$ C. Accordingly, SMT samples show high thermal stability and the presence of silica seems to be critical for the stabilization of the anatase phase. The presence of silicon atoms in the anatase matrix retards the change of facecentered cubic arrangement of oxide ion in anatase into hexagonal packing in rutile because this change is associated with the cleavage of a part of Ti-O bonds [9]. The decrease of the surface energy caused by substitution of the surface $\mathrm{OH}$ groups with oxide ions also contributes to the thermal stability of the present products [15]. The average sizes at different temperatures were calculated, which corresponded to $1.4,4.6,10.1$, and $28.8 \mathrm{~nm}$ for $100,450,650$, and $750^{\circ} \mathrm{C}$, respectively. At temperatures lower than $650^{\circ} \mathrm{C}$, anatase phases are present in relatively small grain sizes. However, 


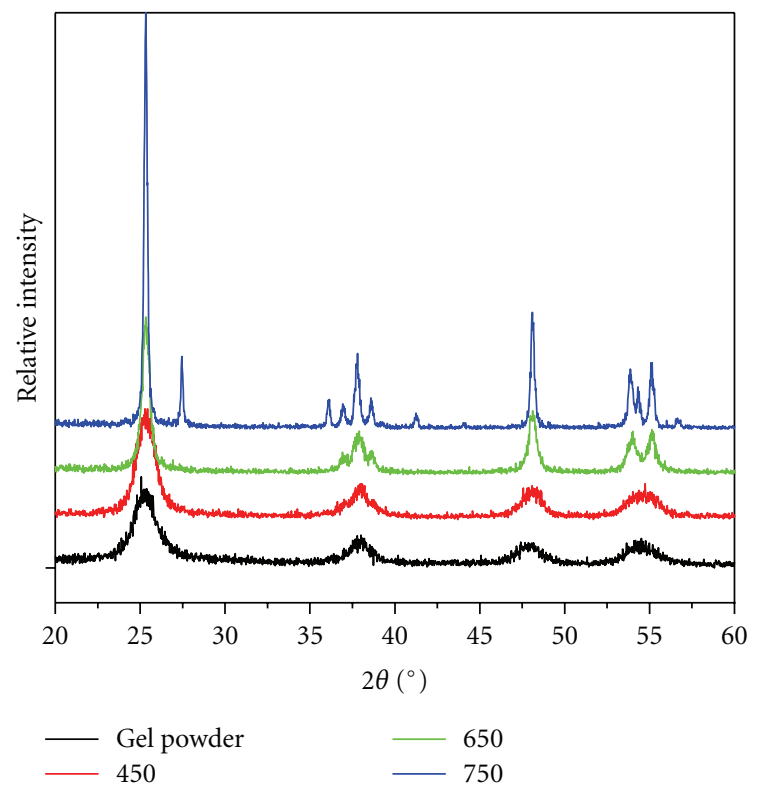

Figure 4: XRD patterns of 0.1-SMT powders calcined at (a) 100, (b) 450 , (c) 650 , and (d) $700^{\circ} \mathrm{C}$ for $1 \mathrm{~h}$.

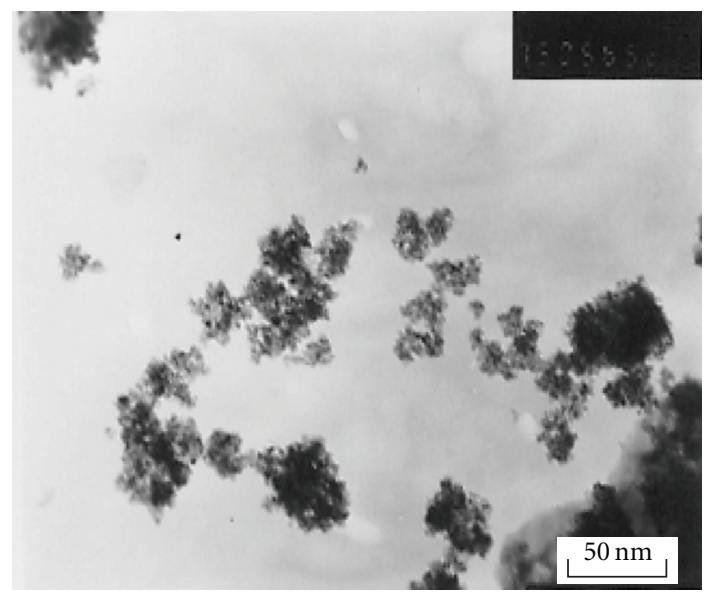

FIGURE 5: TEM image of 0.1-SMT prepared by ultrasonic irradiation hydrolysis and claniced at $550^{\circ} \mathrm{C}$.

at $750^{\circ} \mathrm{C}(\mathrm{Rx}=0.1)$, anatase and rutile phases are both present and the grains of various phases grow dramatically. This is attributable to the fact that the phase transitions accelerate the process of grain growth by providing the heat of phase transformation [16]. The XRD results revealed that the heat treatment induced the increase of crystalline size and phase transformation.

Figure 5 shows TEM photographs of 0.1-SMT powders calcined at $550^{\circ} \mathrm{C}$ for $1 \mathrm{~h}$. It can be seen that the dispersion property of the sample is good. Table 1 indicates that specific surface area of the samples increase with the increase of the silica content. This result confirms that the suitable addition of silica into titania matrix helps to suppress the reduction of surface area at high calcination temperature. It is well noted that the specific surface areas of 0.1-SMT $\left(196 \mathrm{~m}^{2} / \mathrm{g}\right)$ and

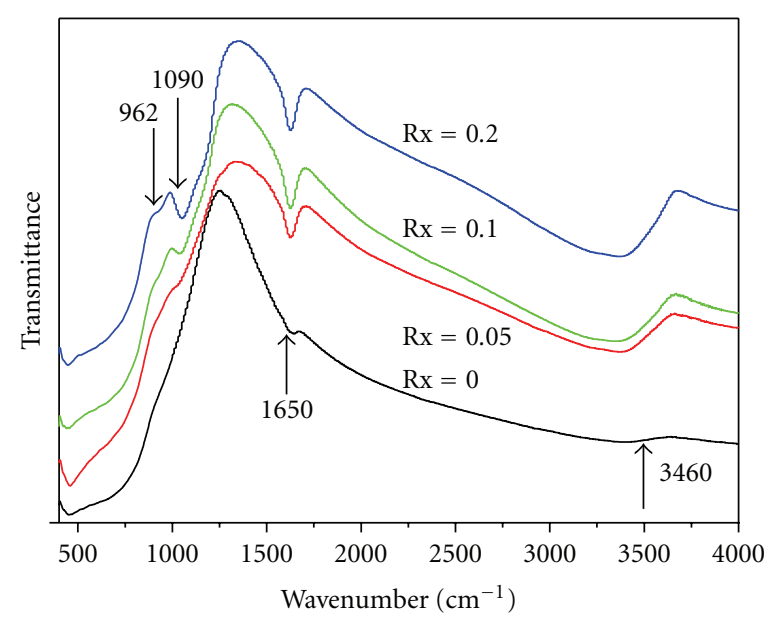

FIgure 6: FT-IR spectra of Rx-SMT powders calcined at $550^{\circ} \mathrm{C}$ for $1 \mathrm{~h}$.

0.1-SMT after $\mathrm{H}_{2} \mathrm{SO}_{4}$ solution treatment $\left(195 \mathrm{~m}^{2} / \mathrm{g}\right)$ are not significantly different.

3.2. FT-IR Spectroscopy. FT-IR spectra of Rx-SMT calcined at $550^{\circ} \mathrm{C}$ for $1 \mathrm{~h}$ are presented in Figure 6. The peak around $1090 \mathrm{~cm}^{-1}$ attributed to the asymmetric stretching vibrations of Si-O-Si band [17], and the Ti-O-Si linkage stretching band appears at about $962 \mathrm{~cm}^{-1}$ [18]. When the ratio of silicon to titanium was over 0.1 , the distinct band for TiO-Si vibration $\left(962 \mathrm{~cm}^{-1}\right)$ was observed. The existence of $\mathrm{Si}-\mathrm{O}-\mathrm{Ti}$ bond in FT-IR analysis may be attributed to the existence of covalent bond between amorphous $\mathrm{SiO}_{2}$ and crystalline $\mathrm{TiO}_{2}$. The band for the asymmetric $\mathrm{Si}-\mathrm{O}-\mathrm{Si}$ stretching vibration was observed for all composite samples, and its intensity was increased with increasing the silicon content. The presence of $\mathrm{Si}-\mathrm{O}-\mathrm{Si}$ bond in FT-IR is caused by the formation of $\mathrm{SiO}_{2}$ in the samples, which is in agreement with the reported result [19]. Besides, Ti-O-Ti bond may be present in the range of 400 to $600 \mathrm{~cm}^{-1}$ [20] for all samples. From these results of FT-IR, it is clear that the silica exists as segregated amorphous phase in the anatase titania powders and some metal-O-metal bonding of Ti-O-Si, which result from formation of a new ternary amorphous SixTiyOz phase as there is no match in the XRD analysis and/or existence of covalent bond between amorphous $\mathrm{SiO}_{2}$ and crystalline $\mathrm{TiO}_{2}$.

The peak around $1650 \mathrm{~cm}^{-1}$ is due to the bending vibration of $\mathrm{O}-\mathrm{H}$ bond, which is assigned to the chemisorbed water, and the peak around $3460 \mathrm{~cm}^{-1}$ is assigned to the stretching mode of $\mathrm{O}-\mathrm{H}$ bond and related to free water [21]. This water band was increased with increasing the ratio of silica to titanium. This is due to the fact that silica has the capability to absorb water in air [22]. In addition, when titania was embedded with silica, crystallite growth was suppressed and the surface area was kept larger (as shown in Table 1), and in this case, the capability to hold absorbed water became larger.

FT-IR spectra of Rx-SMT after $\mathrm{H}_{2} \mathrm{SO}_{4}$ treatment were presented in Figure 7. The peak corresponding to $1244 \mathrm{~cm}^{-1}$ 


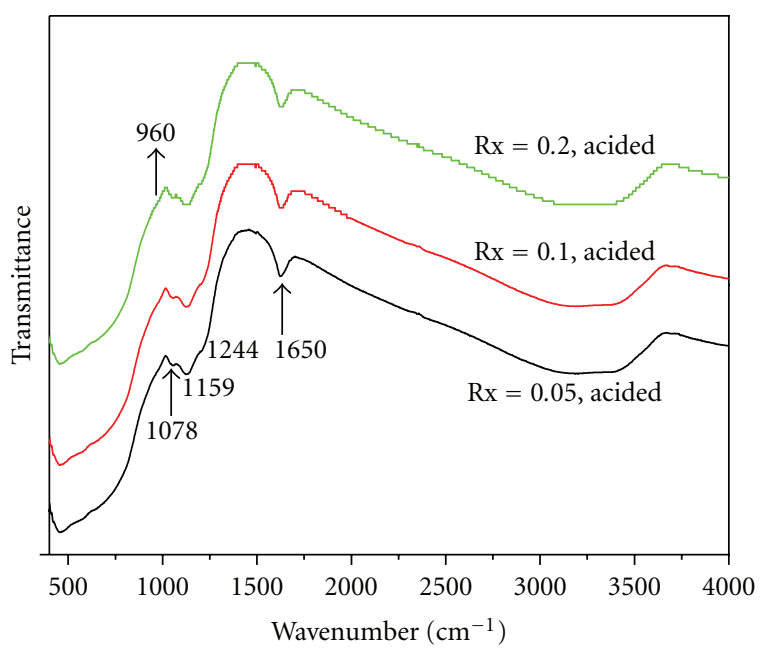

FIGURE 7: FTIR spectra of Rx-SMT powders treated by $1 \mathrm{M} \mathrm{H}_{2} \mathrm{SO}_{4}$ solution. $\mathrm{Rx}=0.05,0.1$, and 0.2 .

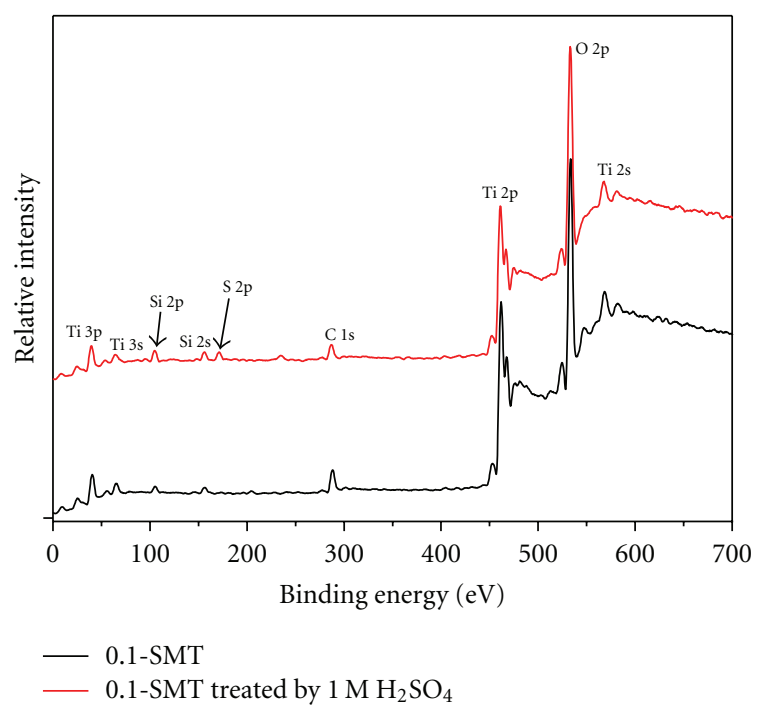

Figure 8: XPS spectra of 0.1 -SMT calcined at $550^{\circ} \mathrm{C}$ for $1 \mathrm{~h}$ and $0.1-\mathrm{SMT}$ treated by $\mathrm{H}_{2} \mathrm{SO}_{4}$ solution.

is the stretching frequency of $\mathrm{S}=\mathrm{O}$, and the peaks corresponding to 1159 and $1078 \mathrm{~cm}^{-1}$ are the characteristic frequencies of $\mathrm{SO}_{4}{ }^{2-}$, which indicated the chelatometric coordinated adsorption of $\mathrm{SO}_{4}{ }^{2-}$ on SMT. The sulfate ion, both in surface and bulk, creates high surface acidity to improve the photocatalytic activity [23].

3.3. XPS Studies. Figure 8 shows the XPS spectrum of 0.1SMT powders heat-treated at $550^{\circ} \mathrm{C}$ for $1 \mathrm{~h}$ and 0.1 -SMT treated by $1 \mathrm{M} \mathrm{H}_{2} \mathrm{SO}_{4}$ solution. XPS peaks show that the 0.1-SMT powders contain nly $\mathrm{Ti}, \mathrm{O}, \mathrm{Si}$, and a trace amount of carbon. The following binding energies are used in our quantitative measurements: Ti $2 \mathrm{p}$ at $460.10 \mathrm{eV}, \mathrm{O} 1 \mathrm{~s}$ at $531.35 \mathrm{eV}$, Si $2 \mathrm{p}$ at $103.8 \mathrm{eV}$, and $\mathrm{C} 1 \mathrm{~s}$ at $286.20 \mathrm{eV}$. The atomic ratio of $\mathrm{Ti}: \mathrm{O}: \mathrm{Si}$ is about $1: 2.13: 0.13$, which is higher than the nominal atomic composition of $\mathrm{TiO}_{2}$, indicating that silica atoms are partially concentrated on the surface region of the titania particles [7]. The C element is ascribed to the residual carbon from precursor solution and the adventitious hydrocarbon from the XPS instrument itself. It is easily observed that $0.1-\mathrm{SMT}$ treated by $1 \mathrm{M} \mathrm{H}_{2} \mathrm{SO}_{4}$ solution contains $\mathrm{Ti}, \mathrm{O}, \mathrm{Si}, \mathrm{S}$, and a trace amount of carbon. The binding energies of $\mathrm{Ti} 2 \mathrm{p}, \mathrm{O} 1 \mathrm{~s}, \mathrm{Si}, \mathrm{S}$, and $\mathrm{C} 1 \mathrm{~s}$ are $460.70,531.9,105,171.1$, and $286.45 \mathrm{eV}$, respectively. It is easily noted from the figure that the binding energy of $\mathrm{Ti}_{2} \mathrm{p}$ in 0.1-SMT after $\mathrm{H}_{2} \mathrm{SO}_{4}$ treatment is higher than that of 0.1SMT before $\mathrm{H}_{2} \mathrm{SO}_{4}$ treatment; the higher binding energy is helpful to improve its photocatalytic activity.

3.4. UV-Vis Spectra. As a photocatalyst, the wavelength distribution of the absorbed light is one of the important properties regardless of the quantum yield. Figure 9 shows the UV-Vis diffuse reflectance spectra (UV/Vis DRS) of prepared powders with the different silica content. Absorption edge of rutile $(R x=0)$ is found to be at the shorter wavelength than that of anatase. Compared Rx-SMT samples with pure titania sample, the absorption spectrum of the RxSMT samples show a stronger absorption in the UV-visible range and a blue shift in the band gap absorption edge was observed in all SMT samples. The blue shift of absorption of a photocatalyst means that the photocatalyst has a greater oxidation-reduction potential and enhance the absorption, which will improve its photocatalytic activity [24].

The energy band gap of prepared samples could be estimated from a plot of $(\alpha h \gamma)$ 1/2 versus photon energy $(h \gamma)$. The intercept of the tangent to the plot will give a good estimation of the band gap energy for indirect band gap materials such as $\mathrm{TiO}_{2}[25,26]$. The absorption coefficient $\alpha$ can be calculated from the measured absorbance $(A)$ using the following equation:

$$
\alpha=\frac{2.303 \rho 10^{3}}{l c M} A,
$$

where the density $\rho=3.9 \mathrm{~g} \mathrm{~cm}^{-3}$, molecular weight $M=$ $79.9 \mathrm{~g} \mathrm{~mol}^{-1}, c$ is the molar concentration of $\mathrm{TiO}_{2}$, and $l$ is the optical path length.

The calculated band gap energies of all silica-modified samples with different Rx values $(0,0.05,0.1$, and 0.2$)$ are about $2.97 \mathrm{eV}, 3.29,3.31$, and $3.34 \mathrm{eV}$, respectively. The above results imply that the absorption edge was clearly shifted toward shorter wavelengths for all SMT samples.

3.5. Photocatalytic Activity. As the photocatalytic mechanism suggests, both photocatalysts and a light source are necessary for the photo-oxidation reaction to occur [6]. A control experiment was conducted on three different conditions: (i) in the dark in presence of 0.1-SMT, (ii) only UV irradiation without photocatalyst, and (iii) under UV illumination in presence of 0.1-SMT. In all above conditions, the initial concentration of Methyl orange is $20 \mathrm{mg} / \mathrm{L}$. In Figure 1, the concentration of $\mathrm{MO}$ is plotted as a function of reaction time.

As can be seen in Figure 10, in the dark, $0.9 \%$ of the initial substrate disappeared after $1 \mathrm{~h}$ of continuous stirring due to the adsorption phenomena. Over this time, abatement 


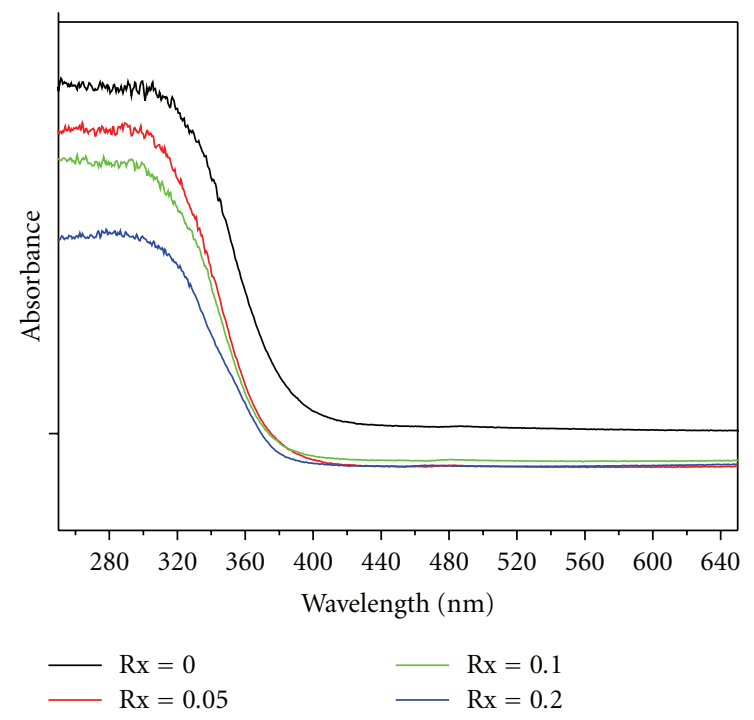

FIgUre 9: UV-Vis spectra of Rx-SMT with different Si/Ti ratios. $\mathrm{Rx}=0,0.05,0.1$, and 0.2 .

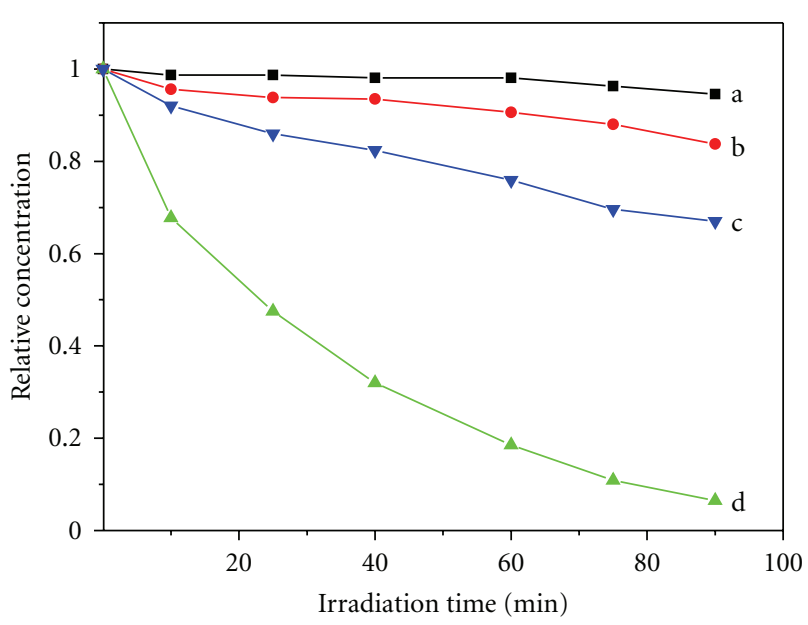

FIgure 10: The variation of MO and TOC concentrations by photocatalytic technology with 0.1-SMT; (a) MO-dark experiment; (b) MO-direct photolysis; (c) TOC-photocatalysis; (d) MOphotocatalysis.

of $5.4 \%$ after $1.5 \mathrm{~h}$ was detected. In direct photolysis, about $8 \%$ disappearing efficiency was observed during the $1 \mathrm{~h}$ irradiation; and $17 \%$ of the initial methyl orange disappeared after $1.5 \mathrm{~h}$. When aqueous 0.1-SMT suspension was exposed to UV light, the concentration of MO decrease markedly. About $68-82 \%$ of methyl orange was bleached within 40-60 mins of time experiment, respectively. It can be clearly seen from Figure 10 that $93.5 \%$ of methyl orange in aqueous solution was photocatalytically degraded, and its corresponding mineralization efficiency was only $33 \%$. It indicated that the complete mineralization of Methyl orange took more time than degradation.
TABLE 2: The kinetics constants and regression coefficients of methyl orange photocatalysis on Rx-SMT and Degussa P-25 titania.

\begin{tabular}{lccc}
\hline Photocatalyst & $\begin{array}{c}\text { Kinetic } \\
\text { constant } \\
\left(\mathrm{min}^{-1}\right)\end{array}$ & $r^{2}$ & $\begin{array}{c}\text { Ratio of } K \text { to } \\
K_{\mathrm{P} 25}\end{array}$ \\
\hline $\mathrm{Rx}=0$ & $K_{0}=0.0015$ & 0.9398 & 0.0789 \\
$\mathrm{Rx}=0.05$ & $K_{1}=0.0234$ & 0.9949 & 1.2316 \\
$\mathrm{Rx}=0.1$ & $K_{2}=0.0296$ & 0.9952 & 1.5579 \\
$\mathrm{Rx}=0.2$ & $K_{3}=0.0149$ & 0.9956 & 0.7842 \\
$\begin{array}{l}\text { Degussa P-25 } \\
\text { titania }\end{array}$ & $K_{\mathrm{P} 25}=0.019$ & 0.9977 & 1 \\
\hline
\end{tabular}

The photocatalytic activity of Rx-SMT powders is affected by various factors, such as the doping silica content, calcined temperature, and sulfuric acid treatment.

3.6. Doping Silica Content. The photocatalytic activity of the prepared SMT powders for the decomposition of methyl orange was investigated as a function of silica content. The photocatalytic degradation follows pseudo first-order kinetics. The results are presented in Figure 11 and Table 2. It is clearly seen that the photocatalytic degradation rate of methyl orange firstly increased with increasing the silica content when the range of silica content was from 0 to 0.1 , it may be due to the decrease of average sizes as shown in the XRD analysis in Figure 3 and the increase of surface hydroxyl group as shown in the analysis of FT-IR in Figure 4. However, higher silica content $(>0.1)$ did not favor the further enhancement of the photoactivity of SMT powders because the crystallinity of anatase decreased in spite of the larger specific surface area (Table 2), and $\mathrm{SiO}_{2}$ did not exhibit photocatalytic activity. It should be noted that the photocatalytic activity of 0.1-SMT is the best among all the samples and it was about 1.56 times of that of Degussa P25 titania, which is recognized as an excellent photocatalyst [27]. The difference in both of specific surface area and anatase crystallites is responsible for this discrepancy of RxSMT photoactivity and the surface area of Rx-SMT samples were presented in Table 1. Moreover, another reason on enhancement of SMT is ultrasonic irradiation in the preparation of samples; ultrasonic irradiation enhances hydrolysis of titanium and silicon alkoxide, and crystallization of the gel, because ultrasonic cavitation creates a unique environment for hydrolysis of titanium and silicon alkoxide. The similar result has been observed in formaldehyde degradation in silica titania system, which was reported [9].

It can be seen from Figure 11 and Table 2 that pure titania $(\mathrm{Rx}=0)$ shows very poor photocatalytic activity, compared to other samples. This can be easily explained that the sample was mainly composed of rutile phase with poor photocatalytic activity and has low specific surface area.

3.7. Calcined Temperature. It is well known that calcination is a common treatment that can be used to enhance the photoactivity of nanosized photocatalysts [27]. The photocatalytic activity of the prepared 0.1-SMT powders for the decomposition of methyl orange was investigated 


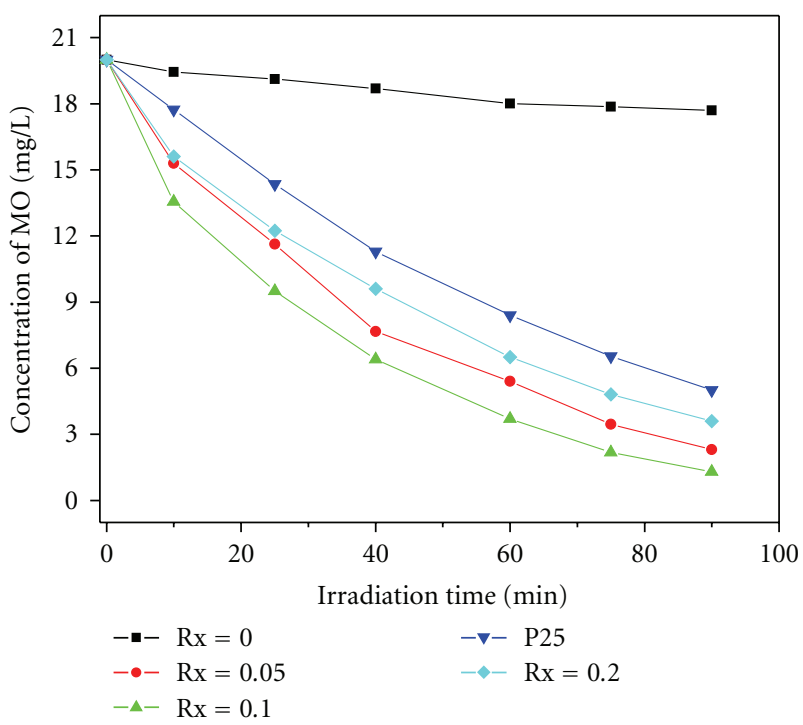

Figure 11: Concentration changes of methyl orange versus UV irradiation time with $\mathrm{Rx}$-SMT photocatalysts calcined at $550^{\circ} \mathrm{C}$ for $1 \mathrm{~h}$.

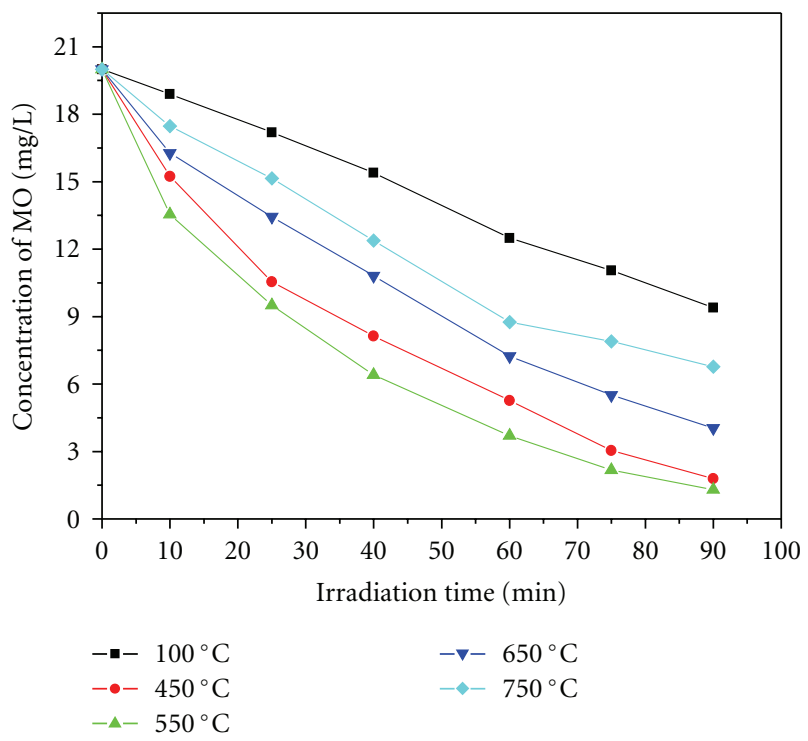

FIGURE 12: Concentration changes of methyl orange versus UV irradiation time with 0.1-SMT powders calcined at 100, 450, 550, 650 , and $750^{\circ} \mathrm{C}$.

as a function of calcination temperature and the result was shown in Figure 12. The 0.1-SMT sample calcined at $100^{\circ} \mathrm{C}$ shows good photocatalytic activity with a reaction rate constant of $7.9 \times 10^{-3} \mathrm{~min}^{-1}$. The reaction rate constant increases with increasing calcination temperature. Enhancing the photocatalytic activity at elevated temperatures can be ascribed to an obvious improvement in the crystallinity of anatase (as shown in Figure 4 ). At $550^{\circ} \mathrm{C}$, the reaction rate constant $k$ reaches the highest value of $2.96 \times 10^{-2} \mathrm{~min}^{-1}$ and it is obviously higher than that of Degussa P-25 titania $\left(k=1.9 \times 10^{-2} \mathrm{~min}^{-1}\right)$. The high photocatalytic activity of

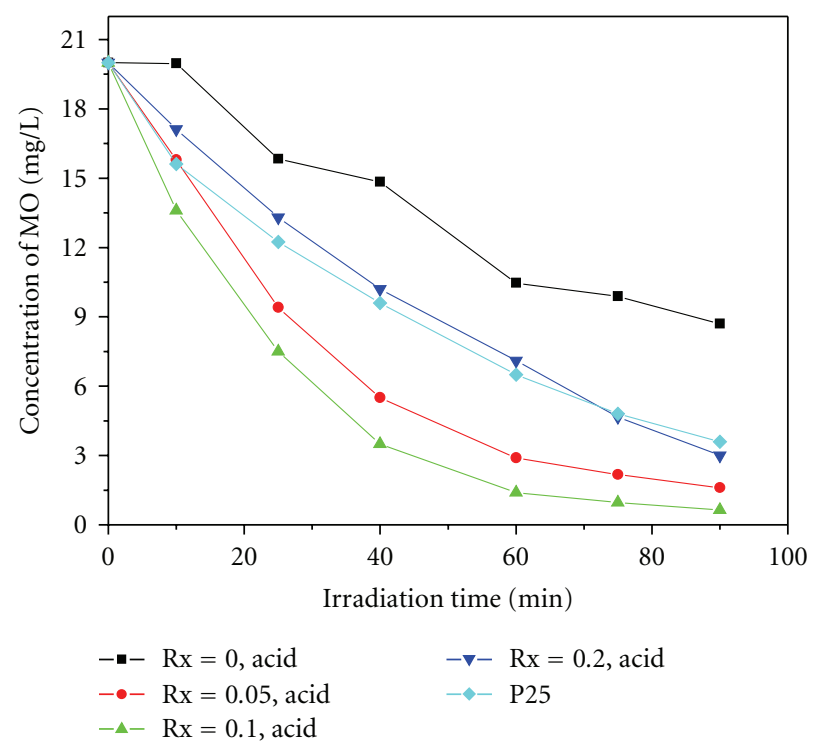

FIgure 13: Concentration changes of methyl orange versus UV irradiation time with different photocatalysts.

TABLE 3: The kinetics constants and regression coefficients of methyl orange photocatalysis on $\mathrm{Rx}$-SMT treated by $\mathrm{H}_{2} \mathrm{SO}_{4}$ solution.

\begin{tabular}{lccc}
\hline Photocatalyst & $\begin{array}{c}\text { Kinetic } \\
\text { constant } \\
\left(\mathrm{min}^{-1}\right)\end{array}$ & $r^{2}$ & $\begin{array}{c}\text { Ratio of } K \text { to } \\
K_{\mathrm{P} 25}\end{array}$ \\
\hline $\mathrm{Rx}=0$, acid & 0.0094 & 0.9627 & 0.4947 \\
$\mathrm{Rx}=0.05$, acid & 0.0295 & 0.9763 & 1.5526 \\
$\mathrm{Rx}=0.1$, acid & 0.0405 & 0.9876 & 2.0558 \\
$\mathrm{Rx}=0.2$, acid & 0.0194 & 0.9873 & 1.0210 \\
\hline
\end{tabular}

the sample calcined $550^{\circ} \mathrm{C}$ is partially due to its large surface area and small crystallite size. Moreover, both of the intense absorption in the UV-visible range and a blue shift in the band gap transition of the SMT samples indicate that more powerful photogenerated holes and electrons can participate in the photocatalytic reactions. Calcination temperatures well above $550^{\circ} \mathrm{C}$ are not desirable. Samples calcined at $750^{\circ} \mathrm{C}$ display relatively poor photocatalytic activity.

3.8. $\mathrm{H}_{2} \mathrm{SO}_{4}$ Treatment. The photocatalytic activity of the prepared $\mathrm{Rx}-\mathrm{SMT}$ powders treated by $\mathrm{H}_{2} \mathrm{SO}_{4}$ solution was also investigated in the paper. The results are shown in Figure 13 and Table 3. By comparing Figure 13 with Figure 11, it is noted from that the photocatalytic activity of all the catalysts is improved after $\mathrm{H}_{2} \mathrm{SO}_{4}$ treatment. The reaction rate constants of $\mathrm{Rx}-\mathrm{SMT}(\mathrm{Rx}=0,0.05,0.1$, and 0.2) after sulfuric acid treatment are 0.0094, 0.0295, 0.0405 , and $0.0194 \mathrm{~min}^{-1}$, respectively. The photocatalytic degradation rate of methyl orange over 0.1-SMT after sulfuric acid treatment was 2 times of that of Degussa P-25 titania and 1.37 times of that 0.1-SMT without sulfuric acid treatment. FTIR results (Figure 7) showed that all samples after $\mathrm{H}_{2} \mathrm{SO}_{4}$ treatment demonstrate enhanced acidity on their surface. It was reported that the enhancement in surface 
acidity improves the activity of a photocatalytic system [28]. Therefore the photocatalytic activity of all samples after $\mathrm{H}_{2} \mathrm{SO}_{4}$ solution treatment was higher than that of the samples without $\mathrm{H}_{2} \mathrm{SO}_{4}$ solution.

3.9. Oxidants Affecting the Photodegradation of MO over $1 \%-F S T_{(R x=10 \%)}$. The effect of different oxidants such as in aqueous solutions on the photodegradation efficiency of $\mathrm{MO}$ in aqueous $1 \%-\mathrm{FST}_{(\mathrm{Rx}=10 \%)}$ suspensions was investigated here, the addition concentration of the oxidants all was $0.01 \mathrm{M}$ and reaction time all was 60 mins. When these oxidants were separately added into reaction solutions, the photodegradation efficiencies corresponding to $\mathrm{KIO}_{4}$, $\left(\mathrm{NH}_{4}\right)_{2} \mathrm{~S}_{2} \mathrm{O}_{8}, \mathrm{H}_{2} \mathrm{O}_{2}$, and control were $95.1 \%, 87.5 \%, 93.2 \%$, and $82 \%$, respectively, which indicated that these oxidants enhance the photodegradation of MO. The higher degree of degradation with the oxidants may be ascribed to formation of highly reactive radical intermediates and the electron capture by these oxidants in the following equations [28].

$$
\begin{gathered}
\mathrm{IO}_{4}{ }^{\bullet-}+h v \longrightarrow \mathrm{IO}_{3}{ }^{\bullet}+\mathrm{O}^{\bullet-} \\
\mathrm{O}^{\bullet-}+\mathrm{H}^{+} \longrightarrow \cdot{ }^{\bullet} \mathrm{OH} \\
\mathrm{S}_{2} \mathrm{O}_{8}{ }^{2-}+h v \longrightarrow 2 \mathrm{SO}_{4}{ }^{--} \\
\mathrm{SO}_{4}{ }^{--}+\mathrm{H}_{2} \mathrm{O} \longrightarrow \cdot \mathrm{OH}+\mathrm{SO}_{4}{ }^{--}+\mathrm{H}^{+} \\
\mathrm{S}_{2} \mathrm{O}_{8}{ }^{2-}+\mathrm{e}_{\mathrm{CB}}{ }^{-} \longrightarrow \mathrm{SO}_{4}{ }^{--}+\mathrm{SO}_{4}{ }^{2-} \\
\mathrm{H}_{2} \mathrm{O}_{2}+h v \longrightarrow \cdot \mathrm{OH}
\end{gathered}
$$

It was well documented that the electron reduction potentials of different species such as $E\left(\mathrm{O}_{2} / \mathrm{O}_{2}^{\bullet-}\right), E\left(\mathrm{H}_{2} \mathrm{O}_{2} /{ }^{\bullet} \mathrm{OH}\right)$ and $E\left(\mathrm{~S}_{2} \mathrm{O}_{8}{ }^{2-} / \mathrm{SO}_{4}{ }^{2-}\right)$ are $-115 \mathrm{mV}, 1150 \mathrm{mV}$, and $1100 \mathrm{mV}$, respectively. It showed that all added oxidants should be more efficient electron acceptors than molecular oxygen to inhibit the electron-hole recombination.

\section{Conclusion}

The Rx-SMT powders calcined at $550^{\circ} \mathrm{C}$ had pure anatase phase without other phases, except that pure titania showed pure rutile phase. XRD and FT-IR results showed that the silicon formed segregated amorphous silica and embedded into anatase titania matrix. BET results indicated that specific surface area increased with increasing the ratio of silica to titanium. Embedding silica into titania matrix increases the thermal stability by suppressing the increase of anatase crystallites and makes it possible to calcine the prepared $\mathrm{Rx}$ SMT powders at high temperature without reducing surface area.

The photocatalytic activity of Rx-SMT powders for the degradation of methyl orange increased with increasing the ratio of silica/titanium up to 0.1 . The highest photocatalytic activity was obtained at $0.1-$ SMT and 1.5 times greater than that of Degussa P-25 titania. It can be confirmed that the quantization of particle size and large surface area by embedding silica into anatase titania matrix are beneficial to improve the photocatalytic activity of samples. The optimum ratio of silica to titania was 0.1 . The photocatalytic degradation of methyl orange was affected by calcination temperatures. The rate constant at $550^{\circ} \mathrm{C}$ was higher than that at other temperature. This may be ascribed to higher specific surface area, small crystallite size, and improvement in the crystallinity of anatase.

Sulfuric acid treatment can enhance photocatalytic activity of SMT powders. The photocatalytic activity of $0.1-$ SMT after treatment by $\mathrm{H}_{2} \mathrm{SO}_{4}$ solution was improved $37 \%$. This increase in activity can be ascribed to high acidity. These oxidants such as $\mathrm{KIO}_{4},\left(\mathrm{NH}_{4}\right)_{2} \mathrm{~S}_{2} \mathrm{O}_{8} \mathrm{H}_{2} \mathrm{O}_{2}$ enhance the photodegradation of $\mathrm{MO}$.

\section{Conflict of Interests}

The authors declare that there is no conflict of interests.

\section{Acknowledgments}

The authors would like to thank Zhejiang Provincial Natural Science Foundation of China (no. Y5080232, no. Y4090605) and International Cooperation Funding of the Ministry of Science and Technology (2010DFA92050) and the Foundation of Zhejiang Provincial Top Key discipline of Environmental Engineering (no. 20080213) for financial support.

\section{References}

[1] T. Peng, A. Hasegawa, J. Qiu, and K. Hirao, "Fabrication of titania tubules with high surface area and welldeveloped mesostructural walls by surfactant-mediated templating method," Chemistry of Materials, vol. 15, no. 10, pp. 2011-2016, 2003.

[2] F. U. Xianzhi, L. A. Clark, Q. Yang, and M. A. Anderson, "Enhanced photocatalytic performance of titania-based binary metal oxides: $\mathrm{TiO}_{2} / \mathrm{SiO}_{2}$ and $\mathrm{TiO}_{2} / \mathrm{ZrO}_{2}$," Environmental Science and Technology, vol. 30, no. 2, pp. 647-653, 1996.

[3] A. A. S. Alfaya, Y. Gushikem, and S. C. De Castro, "Highly dispersed phosphate supported in a binary silica-titania matrix: preparation and characterization," Chemistry of Materials, vol. 10, no. 3, pp. 909-913, 1998.

[4] K. Y. Jung and S. B. Park, "Anatase-phase titania: preparation by embedding silica and photocatalytic activity for the decomposition of trichloroethylene," Journal of Photochemistry and Photobiology A, vol. 127, no. 1-3, pp. 117-122, 1999.

[5] D. W. Lee, S. K. Ihm, and K. H. Lee, "Mesostructure control using a titania-coated silica nanosphere framework with extremely high thermal stability," Chemistry of Materials, vol. 17, no. 17, pp. 4461-4467, 2005.

[6] R. Mariscal, M. López-Granados, J. L. G. Fierro, J. L. Sotelo, C. Martos, and R. Van Grieken, "Morphology and surface properties of titania-silica hydrophobic xerogels," Langmuir, vol. 16, no. 24, pp. 9460-9467, 2000.

[7] N. Hüsing, B. Launay, D. Doshi, and G. Kickelbick, "Mesostructured silica-titania mixed oxide thin films," Chemistry of Materials, vol. 14, no. 6, pp. 2429-2432, 2002.

[8] V. Lafond, P. H. Mutin, and A. Vioux, "Control of the texture of titania-silica mixed oxides prepared by nonhydrolytic solgel," Chemistry of Materials, vol. 16, no. 25, pp. 5380-5386, 2004. 
[9] Z. M. El-Bahy, A. A. Ismail, and R. M. Mohamed, "Enhancement of titania by doping rare earth for photodegradation of organic dye (Direct Blue)," Journal of Hazardous Materials, vol. 166, no. 1, pp. 138-143, 2009.

[10] D. Z. Li, Y. Zheng, X. Z. Fu, and P. Liu, " $\mathrm{SO}^{2-} / \mathrm{TiO}_{2}$ catalyst prepared by microwave method and the research of its photocatalytic oxidation activity," Acta Physico, vol. 17, no. 3, pp. 270-272, 2001.

[11] S. Brunauer, P. H. Emmett, and E. Teller, "Adsorption of gases in multimolecular layers," Journal of the American Chemical Society, vol. 60, no. 2, pp. 309-319, 1938.

[12] J. C. Yu, J. Yu, W. Ho, Z. Jiang, and L. Zhang, "Effects of F doping on the photocatalytic activity and microstructures of nanocrystalline $\mathrm{TiO}_{2}$ powders," Chemistry of Materials, vol. 14, no. 9, pp. 3808-3816, 2002.

[13] J. Lin, Y. Lin, P. Liu, M. J. Meziani, L. F. Allard, and Y. P. Sun, "Hot-fluid annealing for crystalline titanium dioxide nanoparticles in stable suspension," Journal of the American Chemical Society, vol. 124, no. 38, pp. 11514-11518, 2002.

[14] S. Iwamoto, S. Iwamoto, M. Inoue, H. Yoshida, T. Tanaka, and K. Kagawa, "XANES and XPS study of silica-modified titanias prepared by the glycothermal method," Chemistry of Materials, vol. 17, no. 3, pp. 650-655, 2005.

[15] S. R. Yoganarasimhan and C. N. R. Rao, "Mechanism of crystal structure transformations: III. Factors affecting the anataserutile transformation," Transactions of the Faraday Society, vol. 58, pp. 1579-1589, 1962.

[16] A. Duran, C. Serna, V. Fornes, and J. M. Fernandez Navarro, "Structural considerations about $\mathrm{SiO}_{2}$ glasses prepared by solgel," Journal of Non-Crystalline Solids, vol. 82, no. 1-3, pp. 6977, 1986.

[17] D. C.M. Dutoit, M. Schneider, and A. Baiker, "Titania-silica mixed oxides. I. Influence of sol-gel and drying conditions on structural properties," Journal of Catalysis, vol. 153, no. 1, pp. 165-176, 1995.

[18] L. J. Zhao, S. S. Yan, B. Z. Tian, J. L. Zhang, and M. Anpo, Materials Letters, vol. 60, pp. 395-399, 2005.

[19] A. Amlouk, L. El Mir, S. Kraiem, and S. Alaya, "Elaboration and characterization of $\mathrm{TiO}_{2}$ nanoparticles incorporated in $\mathrm{SiO}_{2}$ host matrix," Journal of Physics and Chemistry of Solids, vol. 67, no. 7, pp. 1464-1468, 2006.

[20] J. Rubio, J. L. Oteo, M. Villegas, and P. Duran, "Characterization and sintering behaviour of submicrometre titanium dioxide spherical particles obtained by gas-phase hydrolysis of titanium tetrabutoxide," Journal of Materials Science, vol. 32, no. 3, pp. 643-652, 1997.

[21] Z. Zhang, C. C. Wang, R. Zakaria, and J. Y. Ying, "Role of particle size in nanocrystalline $\mathrm{TiO}_{2} \mathrm{i}$-based photocatalysts," Journal of Physical Chemistry B, vol. 102, no. 52, pp. 1087110878, 1998.

[22] C. Anderson and A. J. Bard, "Improved photocatalytic activity and characterization of mixed $\mathrm{TiO}_{2} / \mathrm{SiO}_{2}$ and $\mathrm{TiO}_{2} / \mathrm{Al}_{2} \mathrm{O}_{3}$ materials," Journal of Physical Chemistry B, vol. 101, no. 14, pp. 2611-2616, 1997.

[23] E. K. Luo, B. S. Zhu, and J. S. Luo, Semiconductor Physics, Electronics Industry Press, Beijing, china, 2003.

[24] M. M. Rahman, K. M. Krishna, T. Soga, T. Jimbo, and M. Umeno, "Optical properties and X-ray photoelectron spectroscopic study of pure and $\mathrm{Pb}$-doped $\mathrm{TiO}_{2}$ thin films," Journal of Physics and Chemistry of Solids, vol. 60, no. 2, pp. 201-210, 1999.

[25] C. Kormann, D. W. Bahnemann, and M. R. Hoffmann, "Preparation and characterization of quantum-size titanium dioxide," Journal of physical chemistry, vol. 92, no. 18, pp. 5196-5201, 1988.
[26] J. C. Yu, J. Lin, D. Lo, and S. K. Lam, "Influence of thermal treatment on the adsorption of oxygen and photocatalytic activity of $\mathrm{TiO}_{2}$," Langmuir, vol. 16, no. 18, pp. 7304-7308, 2000.

[27] Y. T. Kwon, K. Y. Song, W. I. Lee, G. J. Chio, and Y. R. Do, "Photocatalytic behavior of $\mathrm{WO}_{3}$-loaded $\mathrm{TiO}_{2}$ in an oxidation reaction," Journal of Catalysis, vol. 191, pp. 192-199, 2000.

[28] E. Evgenidou, K. Fytianos, and I. Poulios, "Semiconductorsensitized photodegradation of dichlorvos in water using $\mathrm{TiO}_{2}$ and $\mathrm{ZnO}$ as catalysts," Applied Catalysis B, vol. 59, no. 1-2, pp. 81-89, 2005. 

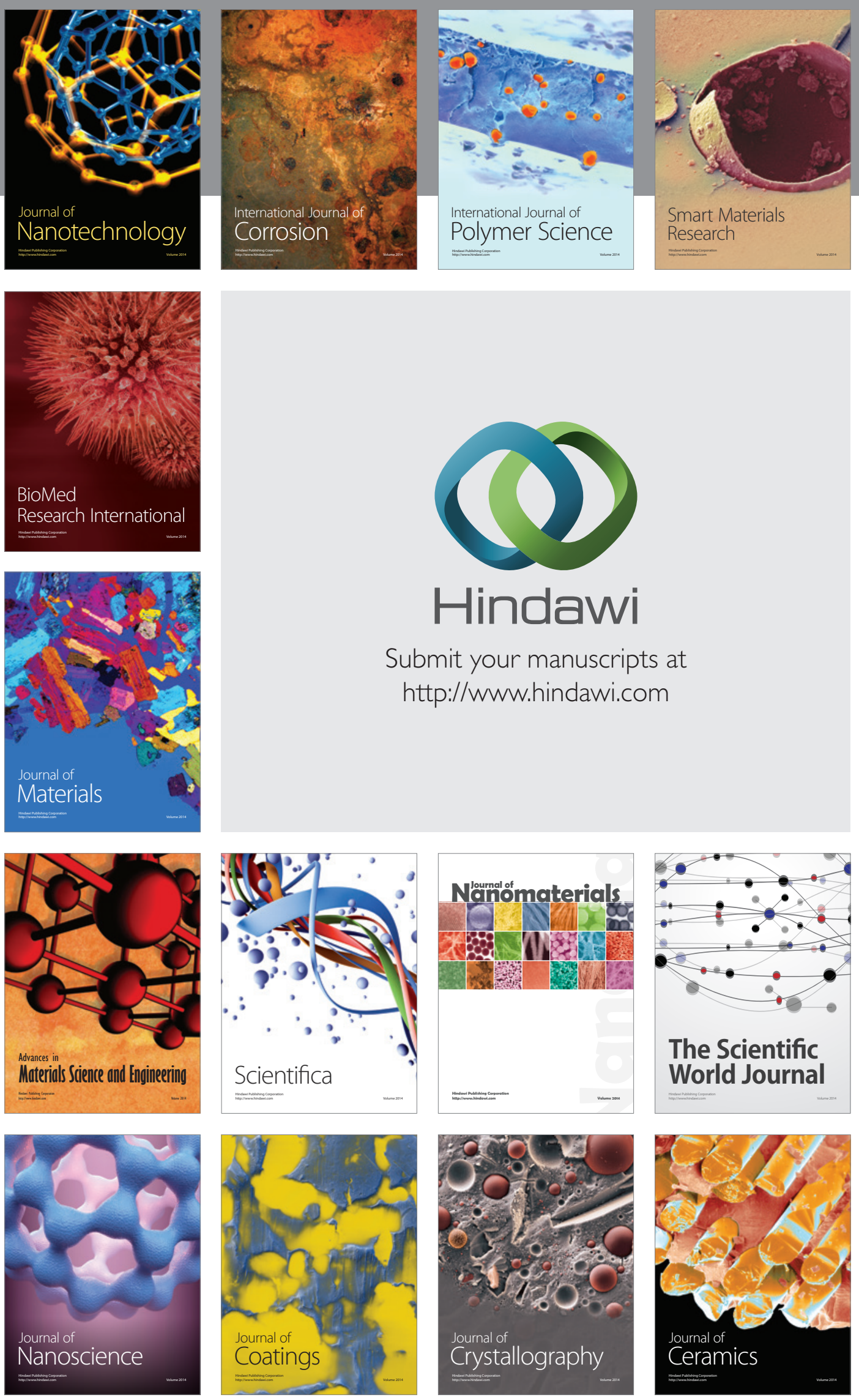

The Scientific World Journal

Submit your manuscripts at

http://www.hindawi.com

\section{World Journal}

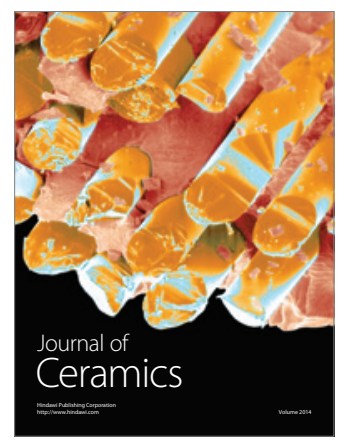

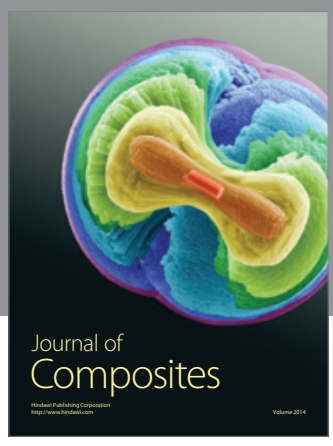
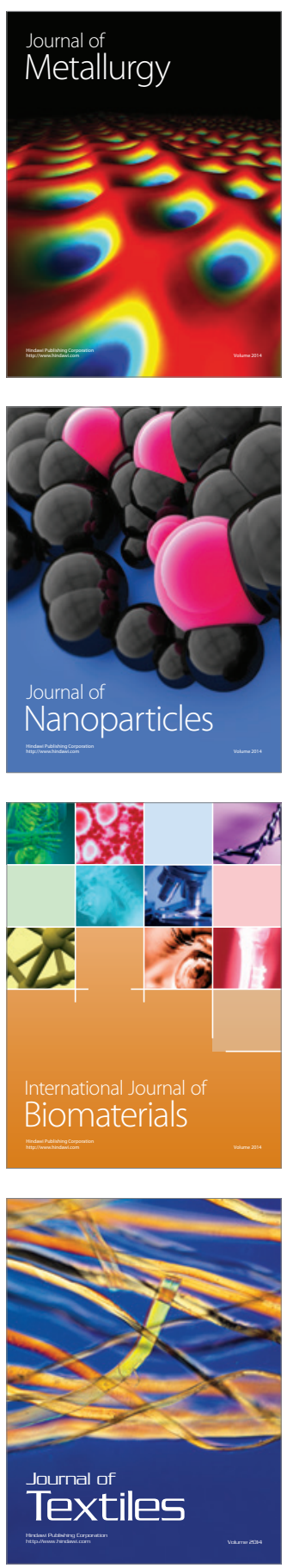